\title{
Centropentaindan: Synthesis and Some Bridgehead Transformations of a Novel Regular Centropolyindan
}

\author{
Dietmar Kuck,* Andreas Schuster and Detlef Gestmann \\ Fakultät für Chemie, Universität Bielefeld, Universitätsstraße 25, D-33615 Bielefeld, Germany
}

The synthesis of a novel centropentacyclic hydrocarbon, centropentaindan 1, has been achieved by fourfold bromination of the readily available difuso-triindan 4 followed by $\mathrm{AlBr}_{3}$-catalysed condensation with two molecules of benzene; functionalization of the two remaining tertiary bridgehead positions of 1 gives the strained, labile dibromide 6, which has been converted into the dimethyl derivative 7, the centrohexacyclic endoperoxide 8, and, again by $\mathrm{AlBr}_{3}$-catalysed condensation with benzene, into centrohexaindan 2.

Among the regular centropolyindans,,$^{1,2}$ all possible members have been synthesized in recent years except for one: centropentaindan 1. This hydrocarbon, bearing five benzo nuclei at a centropentaquinane core, represents the nextlower congener of the highest member of the centropolyindan family, centrohexaindan, 2, which has been obtained for the first time from tetrabenzo[5.5.5.5]fenestrane (fenestrindan) $\mathbf{3}^{3,4}$ by bridgehead bromination and Lewis acid-catalysed condensation with two molecules of benzene. 5

The parent centropentaquinane has remained unknown to date, and only very few organic compounds with centropentacyclic frameworks have been described $.6,7$ Here, we report the first synthesis of the parent pentabenzo analogue, 1 , and some of its conversions at the two bridgehead positions, including the introduction of a single molecule of benzene to give centrohexaindan 2.

The synthesis of 1 comprises only five steps starting from indan-1,3-dione. A three-step method leads to the difusotriindan 4 as described in detail previously. 4,8 While selective bromination of the benzylic methine and methylene $\mathrm{C}-\mathrm{H}$ bonds of 4 proved to be difficult, ${ }^{9}$ we succeeded in converting it into a mixture of stereoisomeric tetrabromides 5 by using 4

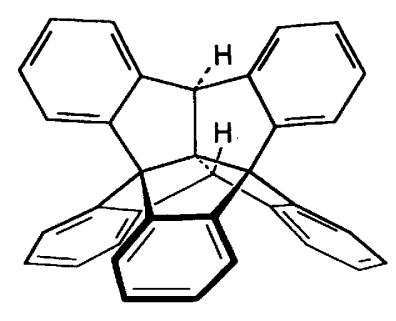

1
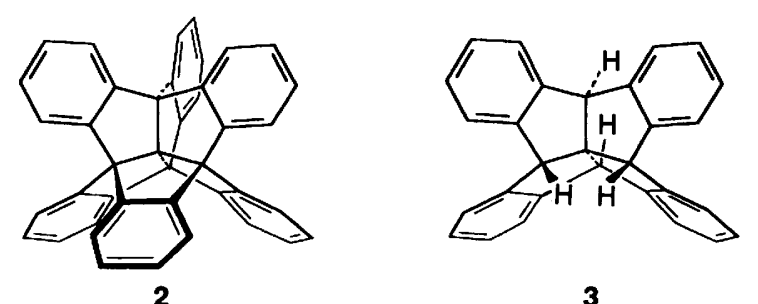

3

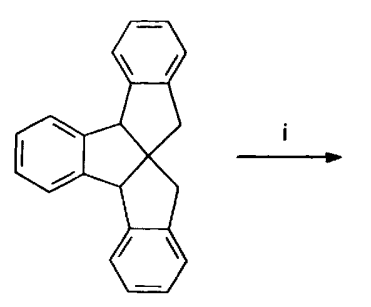

4

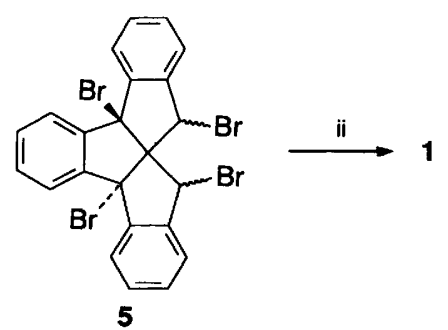

Scheme 1 Reagents and conditions: i, $\mathrm{Br}_{2}$ (4 equiv.), $\mathrm{CCl}_{4}$, hv, heat; ii, $\mathrm{AlBr}_{3}$ (6 equiv.), benzene, 7 days, $25^{\circ} \mathrm{C}$ (yield $88 \%$ from 4 ) equiv. of the reagent (Scheme 1). This is remarkable because of the inevitable presence of a syn-1,3-dibromo grouping in 5 which should be sterically unfavourable. In fact, attempts to introduce even more than four bromine substituents at the central neopentane core of 4 appears to be largely suppressed owing to steric reasons. Subsequent treatment of crude 5 with an excess of aluminium tribromide in benzene solution gives rise to a clean twofold incorporation of benzene giving the title compound 1 , which is isolated in excellent yield ( $88 \%$ based on 4).

The identity of $\mathbf{1}$ is clearly confirmed by spectrometry. $\dagger$ In particular, the molecular $C_{2 v}$ symmetry of 1 effects the fourfold degeneracy of the arene ${ }^{1} \mathrm{H}$ and ${ }^{13} \mathrm{C}$ resonances of the fenestrindan subunit ( $c f .3)$ and twofold degeneracy of those of the remaining benzeno bridge as well as of the $\alpha$-C atoms of the neopentane core. The nucleus of the unique centro-C of 1 resonates at $\delta 83.17$, that is, nearly halfway between the chemical shifts for the lower and higher congeners $(3, \delta$ $71.93,3.4$ and $2, \delta 95.435$ ).

Besides the fenestrindan subunit, the structure of 1 comprises two mutually-fused tribenzotriquinacene moieties, which render its polycyclic skeleton highly rigid. As a consequence, the two remaining bridgehead benzhydrylic $\mathrm{C}-$ $H$ bonds at $C(8 b)$ and $C(16 \mathrm{~b})$ are oriented strictly syn within the plane containing the central $\mathrm{C}(16 \mathrm{~d})$ atom. Nevertheless, and much to our surprise, bromination of 1 with bromine ( 2 equiv.) may be achieved to give the $8 b, 16 b$-dibromocentropentaindan 6 . This dibromide is stable as a crystalline material stored for a few days under argon but decomposes readily in solution. The lability of 6 clearly reflects the unfavourable bisfunctionalization of the two bridgehead positions with bulky bromine atoms.

In spite of the steric strain in 6, several conversions of the bridgehead functionality were performed in analogy to

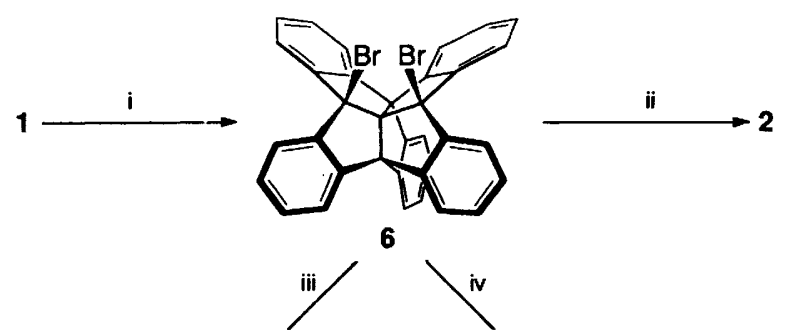

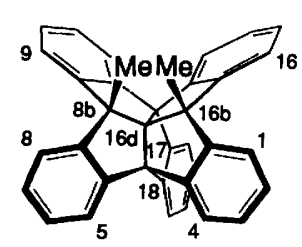

7

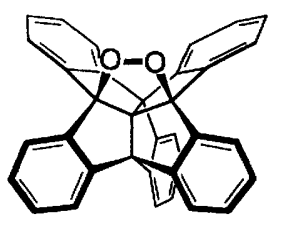

8
Scheme 2 Reagents and conditions: $\mathrm{i}, \mathrm{Br}_{2}$ ( 2 equiv. $), \mathrm{CCl}_{4}$, hv, heat; ii, $\mathrm{AlBr}_{3}$, benzene, 5 days, $25^{\circ} \mathrm{C}$ (yield $57 \%$ from 1); iii, $\mathrm{AlMe}_{3}, n$ hexane, $1 \mathrm{~h}$, heat; iv, $\mathrm{Bu}^{\mathrm{LOOH}}, \mathrm{AgBF}_{4}, \mathrm{CH}_{2} \mathrm{Cl}_{2}, 30 \mathrm{~min} .25^{\circ} \mathrm{C}$ (yields of 7 and 8 both $55 \%$ from 1 ) 
previous results. ${ }^{10}$ For example, 6 is quenched by treatment with trimethylaluminium in hexane to give $8 b, 16 b$-dimethylcentropentaindan 7 in good yield; similarly, Agl-assisted condensation of 6 with tert-butylhydroperoxide leads to endoperoxide 8 (Scheme 2), which represents another member of the growing family of topologically nonplanar organic compounds. ${ }^{10-14}$

While attempts to prepare centrohexaindan 2 , in analogy to the sequence $\mathbf{4} \rightarrow \mathbf{5} \rightarrow \mathbf{1}$, by sixfold bromination of $\mathbf{4}$ and subsequent condensation with three molecules of benzene failed, 2 is obtained in good yield by Lewis acid-catalysed condensation of 6 with benzene (Scheme 2). Thus, the twofold sequential bromination/condensation approach $4 \rightarrow 5 \rightarrow 1 \rightarrow 6$ $\rightarrow 2$ presented here provides a new, efficient synthesis of centrohexaindan 2 , which can be obtained now in seven steps and with $40 \%$ overall yield from indan-1,3-dione. ${ }^{15}$

The synthesis of centropentaindan 1 , as the last hitherto unknown regular centropolyindan, has been achieved following a remarkably short and efficient route. The facile accessibility of 1 promises the synthesis and investigation of a variety of interesting bridgehead functionalized derivatives bearing strictly 1,3-syn orientated substituents at the rigid framework as well as the synthesis of various $8 \mathrm{~b}, 16 \mathrm{~b}$-bridged, centrohexacyclic derivatives of $\mathbf{1}$.

Acknowledgement is made to the Deutsche Forschungsgemeinschaft (DFG, Ku-663 1/2) for financial support of this work.

\section{Received, 3rd November 1993; Com. 3/06576F}

\section{Footnote}

$\dagger$ All new compounds except 6 (see text) gave satisfactory combustional or high-resolution analyses. Selected physical data for 1, 7 and 8. [All ${ }^{1} \mathrm{H}$ NMR measured at $300 \mathrm{MHz}\left(\mathrm{CDCl}_{3}\right)$ and ${ }^{13} \mathrm{C} \mathrm{NMR}$ at 75 $\mathrm{MHz}\left(\mathrm{CDCl}_{3}\right)$ unless otherwise stated.]

1: $\mathrm{mp} 326^{\circ} \mathrm{C} .{ }^{1} \mathrm{H}$ NMR: $\delta 5.08$ (s, $\left.2 \mathrm{H}, 8 \mathrm{~b}-\mathrm{H}, 16 \mathrm{~b}-\mathrm{H}\right), 7.16$ and 7.66 [AA'BB' $4 \mathrm{H}, 20(21)-\mathrm{H}$ and $19(22)-\mathrm{H}$, resp.], 7.21-7.31 [m, $8 \mathrm{H}$, $2(3,6,7,10,11,14,15)-\mathrm{H}], 7.50\left[\mathrm{~d},{ }^{3} J 6.7 \mathrm{~Hz}, 4 \mathrm{H}, 1(8,9,16)-\mathrm{H}\right], 7.86$ [d, ${ }^{3} J 7.1 \mathrm{~Hz}, 4 \mathrm{H}, 4(5,12,13)-\mathrm{H}$ ]; ${ }^{13} \mathrm{C}$ NMR: $\delta 61.8$ [d, C-8b(16b)], 76.3 [s, C-4b(12b)], 83.2 (s, C-16d), 123.4 (d), 123.5 (d), 124.6 (d), 128.1 (d), 145.0 (s), 147.5 (s), 148.3 (s); MS (EI, 70 eV): $\mathrm{m} / \mathrm{z} 442$ (100, $\left.\mathrm{M}^{+\cdot}\right), 365(5), 221(13)$.

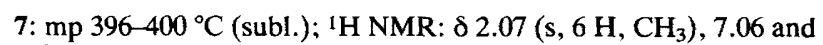
7.52 [AA' BB', 4 H, 20(21)-H and 19(22)-H, resp.], 7.25-7.29 [m, $8 \mathrm{H}$, $2(3,6,7,10,11,14,15)-\mathrm{H}], 7.43[\mathrm{~m}, 4 \mathrm{H}, 1(8,9,16)-\mathrm{H}], 7.83[\mathrm{~m}, 4 \mathrm{H}$, 4(5,12,13)-H]; ${ }^{13} \mathrm{C}$ NMR: $\delta 31.0\left(\mathrm{q}, \mathrm{CH}_{3}\right), 64.0[\mathrm{~s}, \mathrm{C}-8 \mathrm{~b}(16 \mathrm{~b})], 76.0[\mathrm{~s}$, C4b(12b)], 91.4 (s, C-16d), 123.0 (d), 123.2 (d), 127.8 (d), 128.0 (d), 145.7 (s), 148.4 (s), 150.3 (s); MS (EI, $70 \mathrm{eV}): \mathrm{m} / \mathrm{z} 470\left(42, \mathrm{M}^{+\cdot}\right), 455$ $\left(100,[\mathrm{M}-\mathrm{Me}]^{+}\right), 440\left(67,\left[\mathrm{M}-2 \mathrm{Me}^{+\cdot}\right), 220\left(30,[\mathrm{M}-2 \mathrm{Me}]^{2+}\right)\right.$.

8: $\mathrm{mp}>400^{\circ} \mathrm{C}$; ${ }^{1} \mathrm{H}$ NMR: $\delta 7.30$ (overlapped) and $7.83\left[\mathrm{AA}^{\prime} \mathrm{BB}^{\prime}, 4\right.$ H] $7.31(\mathrm{t}$, overlapped, $4 \mathrm{H}), 7.40(\mathrm{t}, 3 \mathrm{~J} 7.5 \mathrm{~Hz}, 4 \mathrm{H}), 7.62(\mathrm{~d}, 3 \mathrm{~J} 7.5$ $\mathrm{Hz}, 4 \mathrm{H}), 7.80\left(\mathrm{~d},{ }^{3} \mathrm{~J} 7.6 \mathrm{~Hz}, 4 \mathrm{H}\right) ;{ }^{13} \mathrm{C}$ NMR $\left(\left[{ }^{2} \mathrm{H}_{6}\right] \mathrm{DMSO}\right): \delta 69.1[\mathrm{~s}$, C-4b(8b)], 103.6 [s, C-8b(16b)], 106.8 (s, C-16d), 124.8(d), 125.3(d), 125.6 (d), 128.8 (d), 129.1 (d), 130.7 (d), 141.1 (s), 145.8(s), 148.9(s); MS (EI, $70 \mathrm{eV}): \mathrm{m} / \mathrm{z} 472\left(41, \mathrm{M}^{+}\right), 456\left(8,[\mathrm{M}-\mathrm{O}]^{+}\right), 440(100,[\mathrm{M}-$ $\left.\left.\mathrm{O}_{2}\right]^{\cdot+}\right), 220\left(45,\left[\mathrm{M}-\mathrm{O}_{2}\right]^{2+}\right)$.

\section{References}

1 D. Kuck, R. Eckrich and J. Tellenbröker, J. Org. Chem., submitted for publication.

2 D. Kuck, in Quasicrystals, Networks, and Molecules of Fivefold Symmetry, ed. I. Hargittai, VCH, New York, 1990, p. 289.

3 D. Kuck and H. Bögge, J. Am. Chem. Soc., 1986, 108, 8107.

4 D. Kuck, Chem. Ber., 1994, 127, 409.

5 D. Kuck and A. Schuster, Angew. Chem., 1988, 100, 1222; Angew. Chem., Int. Ed. Engl., 1988, 27, 1192.

6 R. Keese, A. Pfenninger and A. Roesle, Helv. Chim. Acta, 1979, 62, 326; 1985, 68, 493; L. A. Paquette, R. V. Williams, M. Vazeux and A. R. Browne, J. Org. Chem., 1984, 49, 2194; B. Paisdor and D. Kuck, J. Org. Chem., 1991, 56, 4753.

7 Pagodanes comprise several mutually fused centropentacyclic hydrocarbon frameworks: W.-D. Fessner, G. Sedelmeier, P. R. Spurr, G. Rihs and H. Prinzbach, J. Am. Chem. Soc., 1987, 109, 4626.

8 D. Kuck, Angew. Chem., 1984, 96, 515; Angew. Chem., Int. Ed. Engl., 1984, 23, 508.

9 R. A. Krause, Doctoral Thesis, University of Bielefeld, 1992.

10 D. Kuck, A. Schuster and R. A. Krause, J. Org. Chem., 1991, 56, 3472.

11 D. M. Walba, R. M. Richards and R. C. Haltiwanger, J. Am. Chem. Soc., 1982, 104, 3219; D. M. Walba, Tetrahedron, 1985, 41, 3161.

12 H. E. Simmons III and J. E. Maggio, Tetrahedron Lett., 1981, 22, 287.

13 L. A. Paquette and M. Vazeux, Tetrahedron Lett., 1981, 22, 291.

14 Unpublished results.

15 D. Kuck, B. Paisdor and D. Gestmann, Angew. Chem., submitted for publication. 